\title{
Research on Problems in College English Cross-cultural Teaching
}

\author{
Haiyan Wu, Jing Zeng* \\ Wuhan University of Engineering Science, Wuhan, Hubei 430200
}

Keywords: problems; College English; cross-cultural teaching

\begin{abstract}
Cross-cultural education is an important breakthrough in the reform of college English teaching. More and more attention has been paid to it. However, in the long-term impact of the traditional teaching model, cross-cultural teaching still has many problems in the teaching practice. This paper analyzes the problems in current cross-cultural teaching of college English and proposes coping strategies to help students improve their cross-cultural awareness and cross-cultural competence.
\end{abstract}

\section{Introduction}

With the continuous advancement of China's education reform, the cross-cultural teaching of college English is in line with the needs of social development and has become the future direction of English teaching, which is conducive to improving the level of college English education in China. In the modernization process, the implementation of the college English cross-cultural teaching model can continuously improve the quality of college English teaching and continuously promote the cultural exchanges between China and the West. It has important practical significance for cultivating high-quality talents with Cross-Cultural communicative competence.

\section{Problems Existing in Cross-cultural Teaching of College English}

With the continuous development of college English teaching in recent years, the cross-cultural teaching of college English has also made considerable progress. However, it is deeply influenced by the traditional teaching model, and still exposes many problems in the process of teaching [1].

The guidelines and measures formulated are not targeted. In September 2007, the Ministry of Education had already issued the "Course Requirements for College English Teaching." According to the provisions in the document, college English teaching is divided into three levels: general requirements, higher requirements, and higher requirements. These three levels only made clear requirements for the five skills of college English teaching, listening, speaking, reading, writing, and translation. However, this "requirement" does not make explicit provisions for cross-cultural teaching, and thus gives the cross-cultural teaching of English has caused certain difficulties. The instructional requirements for cross-cultural teaching in the above teaching requirements are not comprehensive and lack of pertinence. As a direct result, there is no detailed policy in the actual operation of college English as a guide, and teachers can only rely on the teacher's own exploration and exploration. Due to different teachers there is a huge difference. In view of this, students of the same university, English majors and non-English majors have shown great differences in the effectiveness of cross-cultural English learning. This difference is also evident between the same levels of different schools.

The design of English textbooks is irrational. Under the current education system, teaching is mainly based on teaching materials. The proportion of cultural content in teaching materials will inevitably affect cross-cultural teaching. At present, there are few organic combinations of cultural content and language content in college English textbooks. Most of the textbooks focus on cultivating language ability, while the organization and arrangement of cultural teaching content is not systematic, and the proportion of articles that are descriptive or technically strong in the textbooks Larger, cultural materials involving spiritual aspects such as values, modes of thinking, and ethics are less. The lack of adequate and satisfactory cultural teaching materials is one of the 
outstanding issues in the cross-cultural teaching of college English in China. Teaching materials are the main basis and guidance for teachers' teaching and student learning, and they are also relying on Chinese students. Solving the problems existing in existing teaching materials is the key to achieving cross-cultural teaching of college English [2].

The concept of English teachers is not strong. In college English Cross-Cultural teaching, the teacher factor is the key to whether cultural teaching can be put into place. First of all, teachers' cultural training and cultural experience are seriously deficient and cultural awareness is weak. As a result, teachers' cultural knowledge is in short supply and their cultural knowledge is not systematic. Secondly, the teachers themselves are the products of traditional English teaching. The teaching methods and ideas accepted by the students who only pay attention to the language form are reflected in their teaching. This is a concrete manifestation of the misunderstanding of teaching philosophy. For many years, when it comes to college English teaching, people naturally think of the teaching of pronunciation, vocabulary, grammar, and other knowledge. When it comes to the need for improved student abilities in college English teaching, they naturally think of "listening, speaking, reading, writing, the translation and training of these five basic skills, the imparting of cultural knowledge and the cultivation of cultural abilities are in a secondary and inferior position.

In the current context, university students' English proficiency test assessment still relies on the National College English Test Band 46. In order to obtain a certificate through examinations, students usually perform English learning according to the requirements of the test content, and the students have the content and skills of the examination. The degree of emphasis and mastery has been much higher than the understanding of the English culture. In the classroom teaching of college English, the teaching content of teachers is also influenced by the assessment methods. The emphasis is on teaching language knowledge to help students cope with examinations. Therefore, cross-cultural knowledge is seldom involved. This kind of test system with 4-6 examinations as the main method not only profoundly affects students' learning methods and learning objectives, but also has a huge impact on teachers' teaching contents and models, resulting in unsatisfactory results in cross-cultural teaching of college English.

Cross-cultural teaching is not closely related to practice In college English cross-cultural teaching, teachers do not attach great importance to the differences between Chinese and Western cultures, mislead college students in their English learning direction, and make cross-cultural teaching unable to closely link with practice, leading to cross-cultural teaching. The effect of cultural teaching has been in an unsatisfactory state. When the students are learning English culture, they cannot understand the sentence order and sentence meaning in depth. This leads to the fact that undergraduates often make mistakes in the practice process, which seriously reduces the enthusiasm and initiative of college students in learning English culture. For example, when communicating with foreign friends in English, we must pay attention to foreign communication methods, correctly use foreigners' logical thinking, and adjust the language order to improve the effectiveness of cross-cultural communication.

In the teaching requirements of college English courses, cross-cultural teaching has given certain teaching requirements, but no specific regulations and standards have been made, leading to problems such as unclear teaching objectives in cross-cultural teaching of college English, and giving college English Cross-Cultural teaching models. The implementation has brought many difficulties. College English teachers only pay attention to the cultivation and improvement of college students' English listening, speaking, reading and writing abilities. They ignore the infiltration of English culture and hinder the spread of English culture. Because there is no clear teaching goal in cross-cultural teaching, which leads to the lack of specific teaching guidance for college English Cross-Cultural teaching implementation, teachers cannot correctly grasp the teaching level of English culture, resulting in serious differences in English cultural learning among college students, giving students comprehensive English learning. The continuous improvement in capabilities has had a serious impact. 


\section{Countermeasures to Improve Cross-Cultural Teaching of College English}

Education policy as a programmatic document for education and teaching plays a key role in teaching. From the curriculum setting, the arrangement of teaching content, and the teaching methods and methods, etc. are affected by the education policy and education policy. Therefore, we should further improve the education policy and strengthen its guiding role. The "Course Requirements for College English Teaching" has written cross-cultural teaching into the "requirements", but there are no specific regulations on the specific schedules, teaching contents, teaching requirements, teaching methods, teaching evaluations, etc., thus lacking pertinence. Therefore, at the same time of college English reform, we should further clarify the relevant requirements of English cross-cultural teaching, so as to play a real guiding role [3].

Teachers play an important role in cross-cultural teaching. Therefore, modern college English teachers should keep pace with the times, abandon the original irrational educational concepts, integrate new educational concepts, and establish cross-cultural awareness. In the teaching process, a variety of teaching methods can be used to fully mobilize the enthusiasm of students and allow students to participate in cross-cultural teaching. In the process of cross-cultural teaching, teachers should continue to learn, constantly improve their own quality, fully understand the similarities and differences between Chinese and Western cultures, and gradually infiltrate the students in the teaching process.

Schools and education authorities should provide English teachers with more training opportunities, especially related to cross-cultural English teaching. Through training, teachers' cultural awareness can be improved, teachers' education and teaching ability can be improved, and teachers' knowledge structure can be improved.

In college English Cross-Cultural teaching, teachers as guides, organizers and coordinators should integrate Chinese and Western cultures. The continuous improvement of teachers' cross-cultural teaching ability and accomplishments is a crucial and important factor in the successful completion of cross-cultural teaching tasks. This directly affects the spread of cross-cultural teaching ideas, the implementation of cross-cultural teaching methods, and cross-cultural teaching activities. In the process of cultivating teachers' Cross-Cultural competence, we should note that this training is a gradual, multi-channel, simultaneous, and diversified process that requires all parties to work together to achieve this. First of all, the college English teaching syllabus should coincide with the teachers' cross-cultural energy and new English teaching resources and teaching model characteristics and distributed cognitive theory in the teaching field, where students can use the Internet to use high-quality educational resources. Simply rely on teaching teachers to teach knowledge.

Although the current college English textbooks have been focused on western culture, as a cross-cultural communication, Oriental culture, especially Chinese culture, is rarely involved in teaching materials. In this case, colleges and universities can combine their teaching situation, organize teachers and students to participate in the preparation of school-based curriculum, and prepare related teaching materials for cross-cultural teaching. In this way, not only the cultural enthusiasm of teachers and students can be mobilized, but also more targeted English cross-cultural teaching materials can be written. Specialized cross-cultural teaching materials will be more conducive to the implementation of college English Cross-Cultural teaching, and will also benefit the further learning of students and the formation of cultural creativity.

The teaching material is the main burden of teaching content, and it is the main basis and guidance for teachers and students to teach and learn. It is the key to achieving teaching goals and improving students' cross-cultural communication skills. Therefore, when selecting teaching materials, we should follow the principle of natural integration of cultural and linguistic content. The layout of content should be based on cultural themes. In each section, the culture should be highlighted and the language should be highlighted to allow students to subconsciously influence the culture. Next, master the use of language better, flexibly and firmly. Language and culture are also used as the teaching purpose and means. The two are inextricably linked. In the textbook, the 
system the theme of culture is an indispensable thread for teaching materials. In fact, the content of language teaching and the above-mentioned cultural content are inseparable and inseparable." When selecting teaching materials, students should fully integrate the actual needs of students in learning a foreign language and the language they speak. The needs of the environment, the structure of knowledge to be constructed, and the levels, etc., contain social customs, history, religion, and values in particular. They introduce the cultural elements of different countries in the West and Chinese traditional culture, and integrate Western and Chinese cultural studies. Students learn how to treat differences correctly.

College English Test Band 4 and Band 6 all influence the English teaching and learning of Cross-Cultural teaching to a certain extent. Therefore, it is imperative to reform the examination system and implement diversified evaluation methods. In education and teaching, "Establish evaluation systems for all aspects, such as classroom teaching, practical teaching, graduation design, and other evaluation index systems, to ensure the quality of education and teaching in an all-round way." [4] Combining formative assessment with summative assessment focuses more on student performance in the teaching process, with a focus on formative evaluation. In the College English Test Band 4-6, cross-cultural content can be appropriately increased. "Intensifying the assessment of humanistic knowledge in English exams will combine the assessment of traditional grammatical structures and vocabulary knowledge with the assessment of cross-cultural knowledge.” [5] Through the increase in the content of the examination to further enhance the teachers and students for the importance of culture. This fundamentally guarantees the feasibility of cross-cultural teaching.

\section{Conclusion}

According to the situation of China's economic development and the current situation of college English teaching, in order to cultivate and improve the Cross-Cultural communication ability of college students, effective countermeasures must be taken to improve the effectiveness and pertinence of college English Cross-Cultural teaching, so as to promote the overall quality of college students. With the continuous increase of educational reform in China, the construction and implementation of college English Cross-Cultural teaching conforms to the teaching requirements of modern college English courses and becomes an important part of college English teaching, which is conducive to the continuous innovation of college English teaching models. It has an important influence on improving college English teaching.

\section{References}

[1] Feng Xiaoling. On the implementation of group cooperative learning from the perspective of distributed cognition [J]. Chinese Adult Education 2014.10

[2] Peng Dongxiao. Opportunities and Challenges of English Classroom Teaching in the "Cloud Environment” [J]. Language and Literature (Foreign Language Education and Teaching) 2015.3

[3] Zhang Wei, Chen Lin, Ding Yan. Learning View in Mobile Learning Era: A Perspective Based on Distributed Cognition Theory [J]. 2010.4.

[4] Zhou Xiaoyong, Wei Chunlin. Information Technology Promotes Language Learning - A Perspective of Distributed Cognitive Theory [J]. Foreign Languages, 2010.4

[5] Cheng Kexin. Discussion on Cross-cultural Teaching Strategies in College English [J]. Jingdezhen College Journal, 2012(3): 130. 